\title{
A CIDADE AMIGÁVEL AO MEIO AMBIENTE NATURAL E A FUNÇÃO SOCIAL DA PROPRIEDADE URBANA.
}

\author{
Hugo Oliveira Veloso ${ }^{1}$ \\ Astreia Soares $^{2}$
}

\begin{abstract}
Resumo: O artigo pretende discutir como uma cidade pode ser considerada amigável e quando será intitulada amigável ao meio ambiente, com o objetivo de revisitar a consolidação evolutiva da doutrina acerca da propriedade imóvel e como a sua constitucionalização ecoou ofertando-lhe função social, o que não mais se reduz à sua razão econômica, mas principalmente o seu ensejo socioambiental, resultado da pesquisa bibliográfica que trata do direito urbanístico constitucional, das leis ambientais, bem como de julgados retratando a importância do meio ambiente natural para que uma cidade seja considerada amigável, como uma contribuição crítica à relação entre direito e meio ambiente.
\end{abstract}

Palavras-chave: Cidades amigáveis. Meio ambiente. Regulação da propriedade urbana. Função social da propriedade. Paisagem urbana.

\section{THE CITY FRIENDLY IN THE NATURAL ENVIRONMENT AND THE SOCIAL FUNCTION OF URBAN PROPERTY}

\begin{abstract}
The article intends to discuss how a city can be considered friendly and when it will be called friendly to the environment, aiming to revisit the evolution of the doctrine about immovable property and how its constitutionalization echoed offering it a social function, which is no longer reduced to its economic reason, but mainly its socio-environmental opportunity, the result of the bibliographic research that deals with constitutional urban law, environmental laws and judgments portraying the importance of the natural environment for a city to be considered friendly, as a critical contribution to the relationship between law and environment environment.
\end{abstract}

Keywords: Friendly cities; Environment; Regulation of urban property; Social function of property; Alterity.

\section{Introdução}

O desafio inicial deste artigo é definir o que seja uma cidade amigável e, partindo de tal significado, relacionar cidade amigável com o direito à preservação do meio ambiente urbano, como um recurso analítico para se compreender o que seria uma cidade amigável ao meio ambiente.

\footnotetext{
1 Pós-graduado em Direito Público pelo Centro Universitário Newton Paiva - ANAMAGES/MG. Pós-graduado em Controle Externo da Gestão Pública Contemporânea pela Pontifícia Universidade Católica de Minas Gerais. Pós-Graduado em Direito Notarial e Registral pela Universidade Anhanguera - UNIDERP. Mestrando pela Universidade FUMEC em Direito Público - Instituições Sociais, Direito e Democracia. Advogado. Endereço de e-mail: hugoveloso@gmail.com. Currículo Lattes: http://lattes.cnpq.br/5845852813789104 2 É Doutora em Humanidades/Sociologia pelo IFCS/UFRJ. É docente e pesquisadora da Universidade FUMEC do curso de graduação em Direito e de seu Programa de Pós-graduação.
} 
Devido a amplitude do tema, a pesquisa que deu origem ao presente artigo se ateve aos objetivos de discutir indicadores de uma cidade amigável ao meio ambiente, descrever as condições jurídicas para a defesa do meio ambiente natural enquanto um bem essencial á vida e à dignidade da pessoa humana e cotejar tais reflexões com as políticas e institutos para a preservação do meio ambiente urbano que se constituem como amparos legais à uma cidade amigável ao meio ambiente.

A pertinência da pesquisa se encerra no fato de percebemos uma urgência no planejamento das cidades que responda a temas como sustentabilidade, função social da propriedade, preservação ambiental e condições urbanas que estejam em diálogo com o fundamento da dignidade da pessoa humana. Tais desafios são globais e exigem ações locais de diversos campos, dentre eles, como não pode deixar de ser, do campo jurídico.

A metodologia adotada foi da pesquisa bibliográfica, por meio da qual pretendeu-se rever e interpretar criticamente o campo teórico jurídico sobre meio ambiente urbano, tendo em vista trazer proposições sobre o Direito, as cidades, seu meu ambiente e uma articulação amigável a seus cidadãos.

O meio ambiente, como cláusula pétrea, assentado na proibição ao retrocesso ambiental se baseou na evolução da propriedade privada como bem sujeito a limitações. Essa propalada evolução, por sua vez, assentou-se na constitucionalização do direito, a partir do movimento secular doutrinado no "bem-estar social", a função social da propriedade não mais se reduz à sua razão econômica, mas também na sua conjuntura socioambiental. Ao conferir à defesa do meio ambiente o caráter fundamental, retirou do proprietário a plena autonomia, prescrevendo, peremptoriamente, que a proteção ao meio ambiente saudável é substância indissociável da função social.

Equalizar os diversos temas constitucionais baseados na sustentabilidade, implica numa ponderação entre os preceitos ambientais e as necessidades de desenvolvimento, o que não pode ser feito sem o devido planejamento, tampouco pode comprometer os espaços e os recursos da cidade e do campo.

A gestão ambiental e o desenvolvimento econômico merecem ser lidos na simbiose constitucional, pois lá estão as suas bases. A manutenção dos processos ecológicos, da biodiversidade e do patrimônio meio ambiental artificial devem ser garantidos pelo manejo planificado por meio da transdisciplinaridade, sem que haja a hierarquização de disciplinas e conhecimentos. 
Se faz necessário que não permaneçamos oblíquos no saber científico e alheios ao crescimento da degradação ambiental. O meio ambiente integra a nossa esfera difusa dos direitos fundamentais e carece não só de uma atividade reguladora que compatibilize crescimento e sustentabilidade, mas de uma ideia ética, transparente e democrática que universalize o seu usufruto, promovendo o bem estar social. O olhar reducionista de apenas uma ou outra área do conhecimento não permite que tenhamos a atenção holística de que a defesa do meio ambiente natural necessita.

Por fim, a cidade amigável ao meio ambiente é uma luz, uma luz verde que sinaliza o caminho para onde devemos jornadear. Se a cidade é constituída de encontros, devemos, portanto, promovê-los, e a cidade clama por esse entrelaçamento de saberes e sabores, da diversidade e da dialética.

\section{0 que é uma Cidade Amigável?}

Uma definição estanque do que seja uma "cidade amigável” seria inócua, pois precisaríamos primeiro supor de onde vem o olhar de quem queira definir o termo, e dependendo dos limites que o observador impuser para extrair o seu significado material enxergaríamos, ao final, que, ou foi amplo demais, ou que tenha sido tão oblíquo quanto a sua capacidade de avistar algo tão vasto como se apresentam os espectros de tal definição.

E qual o motivo para dizermos isso? Quem habita a cidade não é, necessariamente (quase nunca), um grupo homogêneo de pessoas com as mesmas necessidades, hábitos e vontades. A dessemelhança é própria do gênero humano e quem almejar nos incutir a ideia de harmonia entre quereres e necessidades, provavelmente estará tomando para si a própria realidade, no seu privativo círculo de desejos, hábitos e gostos e estendendo-os a todos os demais concidadãos (PORTUGAL, 2008, p. 2).

A virtude da cidade, talvez até a sua indispensabilidade, seja, justamente, o modo de ser heterogêneo de seus habitantes, relembrando que o axioma de um planejamento urbano é de que seja concebido para pessoas e se esse grupo não é singular:

\footnotetext{
A beleza da cidade, a sua riqueza, é em grande parte devedora da fantástica possibilidade de cada uma das diferenças que constitui o conjunto de vontades dos seus habitantes e utilizadores poder encontrar, na complexidade e soma das variadíssimas e desconhecidas oportunidades construídas, o "palco" mais apropriado ao exercício dessas mesmas diferenças.

(...) 'pessoas' não corresponde a um grupo unitário, mas que têm experiências diferentes do ambiente construído e diferentes níveis de satisfação face às políticas
} 
de planeamento, de acordo com as suas características de classe, idade, género, raça, deficiência, cultura ou de estilo de vida (...) (PORTUGAL, 2008, p. 02).

A cidade deve ser vista pelo ângulo de quem a vive e não pela ótica do tecnocrata. A cidade amigável é aquela que a vivência do ser singular e do ser coletivo se encontram em harmonia, seja qual for este ser. $\mathrm{O}$ ente a que se presta viver a cidade pode ser inanimado, vivo, senciente ou não, mas sempre redundará nos desejos e interesses humanos, porquanto estes são o destino, o motivo e a composição da urbe.

Sem adentrar com profundidade ao tema, podemos dizer que o planejamento urbano contemporâneo nas grandes cidades mais intenta "resolver conflitos", dividindo e separando seus habitantes a partir de núcleos de interesse, isso elimina a chance do encontro, para se tornar uma rotina segura e previsível calcada na ideia de que os vários núcleos humanos não precisam/devem conviver.

E se pensarmos a cidade como local dos encontros e de troca, da imprevisibilidade do contato humano, que cidade é essa que queremos? Não podemos diminuir a cidade ao local em que dormimos e trabalhamos, aqui, o verbete "viver", se mostra mais adequado ao que queremos expor, a cidade seria o local onde se vive, por todos os seus mais largos aspectos. Esse "viver" não pode se restringir à vida no local onde se reside e ao local onde se labora. Não podemos reduzir os espaços urbanos a uma única hipótese, que é a de prover a circulação das pessoas, e os espaços públicos servem para vivenciar esses encontros e trocas e não somente para o fluxo humano.

O automóvel passa a ser o mal maior e consequência da inexistência dos encontros, o veículo é a forma de transição do privado (sua casa) para o público (seu trabalho), essa transição extirpa o encontro e a interrelação dos diferentes, a falta da interação causa mais repugnância ao que lhe é alienígena, pois deixa de querer conhecer o outro e o tolerar. $\mathrm{O}$ encontro fomenta e democratiza o espaço urbano.

Vale dizer, cada vez mais o planejamento das cidades é premido da necessidade de chegarmos mais rapidamente aos nossos destinos. Estamos vivenciando planejamentos urbanísticos contemporâneos que suprimem espaços públicos para dar lugar a locais de passagem, para a construção de pontes, viadutos, anéis rodoviários, trevos de interseção viária, ou seja, se planeja, enfim, o "não encontro". As pessoas são compelidas à utilização de seus veículos particulares e se esse transportar é de "porta a porta", com quem convivi? Com quais diferenças interagi? O que aprendi? Quais experiências vivenciei? 
Assim, o investimento urbano é direcionado à solidão dos veículos, e se preciso de ruas apenas para o trânsito, não preciso de espaços públicos, praças, teatros a céu aberto, florestas urbanas, parques. Nesse pensamento, acabamos por não valorizar o caminho onde pode ocorrer o encontro e a convivência, apenas apreciaremos o planejamento viário, subjugando tudo o mais que a cidade pode nos oferecer.

Dito isso, entendemos que a cidade amigável é a cidade que oferta chances de convivência, que não retira dos concidadãos a necessária troca cotidiana de coexistência e tolerância. E dentre as várias possibilidades de óticas e interesses para visitar a "cidade amigável" consideramos uma delas de inegável relevância: o meio ambiente.

\title{
3 Meio Ambiente pela Ótica da Norma Jurídica
}

O meio ambiente aqui considerado é o meio ambiente natural, vez que a doutrina o divide em quatro aspectos: natural, artificial, cultural e laboral.

Em apertada síntese, da obra de Édis Milaré, temos que o meio ambiente pode ser visto em dois aspectos distintos. O primeiro estrito, segundo o qual o meio ambiente simboliza a expressão do patrimônio natural, desprezando tudo o mais que não seja na perspectiva dos recursos naturais. O segundo, ampliando os limites propostos pela ecologia tradicional, abrangendo as dimensões acima lançadas, a saber:

\begin{abstract}
a) ambiente natural ou físico, constituído por elementos abióticos (= sem vida), como o solo, o subsolo, os recursos hídricos, o ar atmosférico e a energia, e por elementos bióticos (= com vida), a exemplo da fauna e da flora; b) ambiente artificial ou antropizado, formado pelas edificações, equipamentos e alterações produzidas pelo homem, enfim, os assentamentos de natureza urbanística e demais construções; c) ambiente cultural, expressado pelo patrimônio artístico, estético, histórico, turístico, paisagístico, arquitetônico etc.; e, por fim, d) ambiente laboral, compreensivo daquele onde as relações de trabalho se desenvolvem e sua relação com a saúde, dignidade e a qualidade de vida do trabalhador (MILARÈ, 2020, RB3.2).
\end{abstract}

O meio ambiente natural, foco do nosso trabalho, merece uma definição mais elaborada, vez que não é de acepção hermética sobre o que seja. Eis a definição trazida pelo inciso, I do artigo $3^{\circ}$, da Lei 6.938, de 31 de agosto de 1981, que dispõe sobre a Política Nacional do Meio Ambiente, seus fins e mecanismos de formulação e aplicação, para a norma seria "meio ambiente, o conjunto de condições, leis, influências e interações de ordem física, química e biológica, que permite, abriga e rege a vida em todas as suas formas" (BRASIL, 1981). 
Podemos dizer que o meio ambiente é algo que compõe a vida de cada ser humano que, por sua vez, também está inserido nesse meio, como um agrupamento de elementos bióticos (fauna e flora) e abióticos (físicos e químicos), estruturados em ecossistemas distintos, sejam naturais ou sociais que o ser humano encontra-se em processo de interação, individual ou social, que propicie o desenvolvimento das atividades humanas, à preservação de recursos naturais e das características substanciais do entorno, dentro dos parâmetros legais e qualitativos definidos. Trata-se, portanto, da agregação de todas as coisas e fatores externos ao indivíduo ou população de indivíduos, suas relações e intercâmbios.

A Constituição da República Federativa do Brasil de 1988 - CRFB/1988 - traz, na cabeça de seu artigo 225 uma conceituação patrimonial do meio ambiente, colocando-o como bem de uso comum do povo, o que na visão de Hely Lopes Meirelles:

\section{(...) no uso comum do povo os usuários são anônimos, indeterminados, e os bens utilizados o são por todos os membros da coletividade - uti universi -, razão pela qual ninguém tem direito ao uso exclusivo ou a privilégios na utilização do bem: o direito de cada indivíduo limita-se à igualdade com os demais na fruição do bem ou no suportar os ônus dele resultantes. Pode-se dizer que todos são iguais perante os bens de uso comum do povo" (MEIRELLES, 2016, p. 641).}

Ao afirmar que "todos têm direito ao meio ambiente ecologicamente equilibrado, bem de uso comum do povo e essencial à sadia qualidade de vida, impondo-se ao Poder Público e à coletividade o dever de defendê-lo e preservá-lo para as presentes e futuras gerações", onde Milaré (2020, RB-3.3) acentua que tal conceituação tem um caráter eminentemente antropocêntrico, consoante a qual "o mundo natural tem valor apenas enquanto atende aos interesses da espécie humana, concepção essa, aliás, muito presente no pensamento ocidental "MILARÉ, 2020, RB-3.3)"

Os conceitos e faces do meio ambiente acima, brevemente delineados, são complementares e interdependentes, assim e para nosso trabalho, questionamos: O meio ambiente construído, portanto, artificial, pode prescindir da existência de espaços livres? A preservação do meio ambiente natural é relevante para a nossa existência?

A resposta parece óbvia... e é.

Quando falamos de cidade amigável não é possível imaginar uma cidade sem que haja preservação do meio ambiente natural, e a importância dessa preservação causou modificações substanciais na legislação brasileira ao longo do tempo, culminando na sua imposição constitucional e não só: o meio ambiente, na concepção do legislador ordinário de 
1988, foi traçado e constituído como cláusula pétrea, a fim de preservar a sua índole de direito fundamental, não é outro o pensamento de Ingo Wolfgang Sarlet e Tiago Fensterseifer que assertivamente afirmam que houve o reconhecimento da proteção ambiental como cláusula pétrea e que a Constituição brasileira, conferiu um "valioso atributo de durabilidade" à proteção ambiental no âmbito ordenamento jurídico-constitucional brasileiro (SARLET, 2020).

A forma como foi constitucionalmente lançada a proteção ambiental funcionaria como barreira à desregulamentação e às alterações casuísticas ao soar de crises artificiais e emergências fictícias, nas palavras de Herman Benjamin (BENJAMIN, 2007, p. 79). A matéria elevada e reforçada ao status de cláusula pétrea visa, também, proteger os direitos fundamentais, com a relevância do supra princípio que é a dignidade da pessoa humana. Atento à garantia de proibição de retrocesso ecológico e ao comando constitucional inseridos nos parágrafos do artigo 225 da CRFB/1988, que ordena progredir na defesa e recomposição dos ambientes naturais, Sarlet afirma que tais "institutos jurídico-constitucionais objetivam blindar o bloco normativo constitucional-ambiental contra eventuais retrocessos" (SARLET, 2020).

Acerca da normatização constitucional na discussão a respeito dos direitos da natureza, percebe-se que há um gradual surgimento doutrinário em torno dos limites de cada Estado em enfocar apenas a sua realidade ecológica, ampliando a perspectiva de proteção ao meio ambiente, posto que não há mais fronteiras normativas para a tal desiderato, pois, gradativamente o Estado vem perdendo a sua exclusividade no domínio constitucional, fazendo cada vez mais sentido falar-se em 'constitucionalismo global'. Com espeque no artigo $5^{\circ}, \S 2^{\circ}$ da CRFB/1988, afirma-se que o controle de convencionalidade abarca o direito fundamental ao meio ambiente saudável, conferindo um status normativo supralegal aos tratados internacionais de que o Brasil seja parte (FENSTERSEIFER, 2021).

Ainda nesse ínterim, vimos há pouco tempo a Corte Interamericana de Direitos Humanos - CIDH, alinhada com esse cenário que desponta, manifestando-se por meio da Opinião Consultiva n. 23/2017 sobre "Meio Ambiente e Direitos Humanos" a proteção jurídica autônoma, ou seja, "em si mesma" da Natureza, encorpando uma tendência a reconhecer a personalidade jurídica e, por fim, os direitos da Natureza. Esta Corte reconheceu, também, a existência de uma relação inegável entre a proteção do meio ambiente e a realização de outros direitos humanos, em que tanto a degradação ambiental e os efeitos 
adversos da mudança climática afetam o desfrute efetivo desses direitos, ressaltando que vários direitos de categoria fundamental requerem, como uma pré-condição necessária para seu exercício, uma qualidade ambiental mínima, e se veem afetados de forma profunda pela degradação dos recursos naturais (CIDH, 2017).

Cidades amigáveis, na nossa visão, propiciam aos seus concidadãos a oportunidade de viver em meio ao meio ambiente saudável e ecologicamente equilibrado. A cidade amigável ao meio ambiente proporciona a permanente defesa do meio ambiente natural, elevado à categoria de bem jurídico essencial à vida, à saúde e à felicidade do homem. Nas cidades vivemos em constante interação com os componentes bióticos e abióticos, as cidades se compõem dos núcleos ambientais acima delineados, natural, artificial, cultural e laboral.

A cidade é, por excelência, o patrimônio ambiental artificial e a CRFB/1988, nos dispositivos relativos à Ordem Econômica e Financeira, artigos 182 e 183, cuidou do tema focalizando o acesso social à propriedade urbana, deixando à norma infraconstitucional a missão de articular a defesa do meio ambiente natural no âmbito das cidades. A Lei 10.257 de 10 de julho de 2011, conhecida como Estatuto da Cidade, regulamentou os artigos acima, contemplando a governança dos espaços urbanos aos municípios e estabelecendo instrumentos de gestão para a consecução dos objetivos locais. O caput do artigo 182 reforçou a relevância da função social da cidade, a garantir o bem-estar de seus habitantes. Não temos dúvida de que o meio ambiente natural saudável e preservado é essencial à saúde humana, por isso, "toda intervenção antrópica no ambiente deve ser no sentido de preservar ou recuperar a sua qualidade, visto que há interesses mútuos entre o meio natural e o ambiente humano" (MILARÉ, 2020, RB-3.8).

Merecem peculiar cuidado os elementos naturais existentes nos assentamentos humanos, pois a saúde de seus habitantes depende da preservação do meio em que vive. A pressão exercida pela invasão antrópica demanda primordial atenção aos programas de saneamento, de conservação, proteção e utilização sustentável (racional) dos recursos naturais, sempre vigilante ao fato do substancial cuidado à cobertura vegetal existente no meio urbano e à volta dele, posto que quase a totalidade dos povoamentos urbanos já apresentaram degradação socioambiental em diversificados modos de poluição.

\section{Política de Reordenação Urbana na Constituição de 1988 e a Obrigação de Preservação do Meio Ambiente Natural no Seio do Tecido Urbano}


A CRFB/1988 reformulou estruturalmente a forma federativa e elevou os munícipios à categoria de ente federativo permanente e autônomo, determinando no Capítulo II, do Título VII a competência para a ordenação do espaço urbano. A forma de federalismo cooperativo traçado nas linhas constitucionais fixou que o ente mais próximo da realidade a ser normatizada e fiscalizada é quem deve receber as prerrogativas para tal mister, assim, com essa reformulação a construção em áreas urbanas passou a ser regida, primordialmente, pelos municípios, por meio de leis municipais e de uso e ocupação do solo, em especial por meio do Plano Diretor, obrigatório às cidades com mais de vinte mil habitantes ( $\$ 1^{\circ}$ do artigo 182$)$. Segue-se, ainda, normas mais específicas, como as de zoneamento e códigos de posturas, todas balizadas pelas leis federais (MILARÉ, 2020, RB-23.22).

O artigo 23 da CRFB/1988 prevê a competência material comum de todos os entes federativos, estabelecendo uma cooperação que, em caso de conflito, utilizar-se-á o denominado critério da preponderância de interesses. Entre as competências fixadas no mencionado dispositivo podemos destacar, como afetas ao direito urbanístico, tangenciando, também, o direito ambiental:

\footnotetext{
III - proteger os documentos, as obras e outros bens de valor histórico, artístico e cultural, os monumentos, as paisagens naturais notáveis e os sítios arqueológicos;

IV - impedir a evasão, a destruição e a descaracterização de obras de arte e de outros bens de valor histórico, artístico ou cultural;

VI - proteger o meio ambiente e combater a poluição em qualquer de suas formas;

VII - preservar as florestas, a fauna e a flora;

IX - promover programas de construção de moradias e a melhoria das condições habitacionais e de saneamento básico;

$\mathrm{X}$ - combater as causas da pobreza e os fatores de marginalização, promovendo a integração social dos setores desfavorecidos;

XII - estabelecer e implantar política de educação para a segurança do trânsito.
}

Da repartição constitucional de competências em matéria urbanística, o artigo 24 prescreve um "condomínio legislativo", fixando uma competência legislativa concorrente. Competindo à União estabelecer "normas gerais" e aos Estados e ao Distrito Federal fixar normas suplementares $\left(\S \S 1^{\circ}\right.$ e $\left.2^{\circ}\right)$. Aos municípios cabem legislar sobre "assuntos de interesse local", por exemplo, a ordenação do solo urbano, de modo que a competência suplementar municipal se exerce para regulamentar as normas legislativas federais e estaduais, inclusive as enumeradas no artigo 24 da CRFB/1988, a fim de particularizar os interesses locais. 
Já no artigo 25 a CRFB/1988 estabelece a atribuição residual dos Estados, na medida em que lhes são reservadas as competências não vedadas pela Constituição $\left(\S 1^{\circ}\right)$, assim como duas outras competências expressas, uma das quais relacionada à matéria urbanística, que é a possibilidade de instituição, por lei complementar de "regiões metropolitanas, aglomerações urbanas e microrregiões, constituídas por agrupamentos de municípios limítrofes, para integrar a organização, o planejamento e a execução de funções públicas de interesse comum (artigo 25, § $3^{\circ}$ )".

No artigo 30 apresentam-se as competências ofertadas aos municípios, a quem compete legislar sobre os temas de interesse local (inciso I); suplementar a legislação federal e a estadual no que for cabível (inciso II); criar, organizar e suprimir distritos, nos termos da legislação estadual (inciso IV); organizar e prestar, de modo direto ou sob o regime de concessão ou permissão, os serviços públicos de interesse local, como o de transporte coletivo (inciso V); promover a adequada ordenação territorial, pelo planejamento e o controle do uso, do parcelamento e da ocupação das cidades (inciso VIII); e, por fim, promover a proteção do patrimônio histórico-cultural da localidade (inciso IX).

A CRFB/1988 ao atribuir à União, aos Estados e ao Distrito Federal a competência para legislar concorrentemente sobre direito urbanístico (artigo 24, I) e aos municípios a competência para promover o ordenamento territorial, mediante planejamento e controle do uso, do parcelamento e da ocupação do solo urbano (artigo 30, VIII) consolidou, nesse ponto, o pacto federativo, o que foi confirmado pelo Supremo Tribunal Federal - STF, quando, em sede da Ação Direta de Inconstitucionalidade - ADI n. 478, decidiu que as normas federais e estaduais de direito urbanístico, às quais os município estão submetidos, devem ser gerais para não tornarem inócua a competência municipal:

(...) a competência municipal, para promover, no que couber, adequado ordenamento territorial, mediante planejamento e controle do uso, do parcelamento e da ocupação do solo urbano - CF, art. 30, VIII - por relacionar-se com o direito urbanístico, está sujeita a normas federais e estaduais (CF, art. 24, I). As normas das entidades políticas diversas - União e Estado-membro - deverão, entretanto, ser gerais, em forma de diretrizes, sob pena de tornarem inócua a competência municipal, que constitui exercício de sua autonomia constitucional (BRASIL, 1996).

O modelo constitucional de federalismo adotado preconizou que a política de ordenação urbana se daria nas três esferas federativas, cada qual com as prerrogativas inerentes ao domínio de suas competências. Para a União coube “instituir diretrizes para o desenvolvimento urbano (artigo 21, XX), o que o fez por meio da já mencionada Lei 10.257/2001, que regulamentou os artigos 182 e 183 da CRFB/1988. Aos municípios compete 
"promover, no que couber, adequado ordenamento territorial, mediante planejamento e controle do uso, do parcelamento e da ocupação do solo urbano" (artigo 30, VIII). A norma nacional materializou os meios pelos quais os municípios executarão sua incumbência, principalmente o Estatuto da Cidade e a Lei 6.766/1979 - Lei de Parcelamento do Solo Urbano.

A chamada interpretação sistêmica da letra da Constituição de 1988 arredondou e aquilatou as várias frentes as quais o operador do direito seria obrigado a lidar. Mesmo não impondo diretamente, fez refletir e espraiar por toda sorte normativa que deveria haver a conjugação de todos os interesses constitucionais nessa Nova Ordem Jurídica, legitimando o princípio do desenvolvimento sustentável (artigos 3, 170 e 225 da CRFB/1988), para que houvesse a integração do desenvolvimento socioeconômico com a conservação da natureza, o Constituinte Originário relacionou, como um dos valores da ordem econômica, nos artigos $1^{\circ}$, III; $3^{\circ}$, I, II, III e IV; 4 , II e IX; 5º II e IV; 170, 182, 183 e 225, a existência digna e o bem de todos com o respeito à capacidade de sustentação, defesa e proteção do meio ambiente e da sadia qualidade de vida, inclusive no ambiente urbano.

A recepção, pela CRFB/1988, da Política Nacional de Meio Ambiente, instituída pela Lei 6.938/1981, representou a manutenção de uma visão que já no ano de 1981 considerava a essencialidade da proteção do meio ambiente. $\mathrm{O}$ artigo $2^{\circ}$, da referida Lei dispõe que "A Política Nacional do Meio Ambiente tem por objetivo a preservação, melhoria e recuperação da qualidade ambiental propícia à vida, visando assegurar, no País, condições ao desenvolvimento socioeconômico, aos interesses da segurança nacional e à proteção da dignidade da vida humana (...)". Vê-se logo que a Lei já antecipara preceitos caros à Nova Ordem que viria em 1988: preservação do meio ambiente, progresso socioeconômico e dignidade da vida humana, mandamentos que são indissociáveis.

No entorno da partição constitucional de competências coube ao município, por meio do Plano Diretor, assegurar aos cidadãos a qualidade de vida, a par de outros direitos e em conexão com as diretrizes estabelecidas no artigo $2^{\circ}$ do Estatuto das Cidades que estabelece que a política urbana tem por objetivo ordenar o pleno desenvolvimento das funções sociais da cidade e da propriedade urbana, deve, também, estimular políticas de prevenção e evitar, entre outros efeitos indesejáveis, a deterioração das áreas urbanizadas, a poluição e a degradação ambiental (artigo $2^{\circ}$, VI, 'f' e 'g'). No mesmo sentido o artigo $2^{\circ}$, XII, prescreve 
que uma das diretrizes é a "proteção, preservação e recuperação do meio ambiente natural e construído, do patrimônio cultural, histórico, artístico, paisagístico e arqueológico".

Édis Miláré pontua que as Diretrizes Gerais do Estatuto das Cidades, no mesmo artigo $2^{\circ}$, I, acentuam o direito a cidades sustentáveis, que compreende o direito ao saneamento ambiental, fator indispensável à qualidade do meio e à qualidade de vida para as presentes e futuras gerações. Esse postulado já se encontrava implícito no artigo $6^{\circ}$ da CRFB/1988, onde são enumerados os direitos sociais (MILARÉ, 2020, RB-37.1 RB-37.8).

A Ordem Jurídica de 1988 não descurou, também, da função social da propriedade urbana ou rural, ao mesmo tempo que não se pode pensar de uma função social da propriedade sem que haja efetiva proteção ao meio ambiente. Nessa reflexão sobre o assunto, podemos dizer que a função social da propriedade urbana alterou substancialmente o direito do proprietário de dispor livremente dela, condicionando seu uso e fruição ao interesse social, funcionalizando-a, não apenas por um interesse econômico, mas também, e sobretudo, ambiental, a justificar o aforismo de que "toda propriedade privada é gravada por uma hipoteca social", como é tranquilamente aceito nos Estados modernos (MILARÉ, 2020, RB37.6).

\subsection{Institutos Infraconstitucionais Destinados à Preservação do Meio Ambiente Natural no Espaço Urbano}

Vários são os meios de se promover a preservação do meio ambiente natural no interior das cidades. Citaremos alguns que consideramos mais pertinentes ao tema "cidades amigáveis ao meio ambiente", principalmente os espaços verdes urbanos.

O Estatuto das Cidades, no seu artigo 26, ao tratar do direito de preempção, dá ao Poder Público competência para adquirir e dispor de áreas necessárias à criação de espaços públicos de lazer e áreas verdes (inciso VI), à criação de unidades de conservação ou proteção de outras áreas de interesse ambiental (inciso VII), bem como à proteção de áreas de interesse histórico, cultural ou paisagístico (inciso VIII).

Especificamente, em relação às áreas verdes urbanas, de acordo com o artigo $3^{\circ}$, XX, do Código Florestal, estas compreendem os

(...) espaços, públicos ou privados, com predomínio de vegetação, preferencialmente nativa, natural ou recuperada, previstos no Plano Diretor, nas Leis de Zoneamento Urbano e Uso do Solo do Município, indisponíveis para 
construção de moradias, destinados aos propósitos de recreação, lazer, melhoria da qualidade ambiental urbana, proteção dos recursos hídricos, manutenção ou melhoria paisagística, proteção de bens e manifestações culturais (BRASIL, 2012).

O Código Florestal dispõe no seu artigo 25, que o Poder Público municipal contará, para o estabelecimento de áreas verdes urbanas, com (i) o exercício do direito de preempção para aquisição de remanescentes florestais relevantes, nos termos do Estatuto da Cidade; (ii) a transformação das Reservas Legais em áreas verdes nas expansões urbanas; (iii) o estabelecimento de exigência de áreas verdes nos loteamentos, empreendimentos comerciais e na implantação de infraestrutura; e (iv) aplicação em áreas verdes de recursos oriundos da compensação ambiental.

As respostas para a consecução dos objetivos constitucionais tanto na esfera interfederativa, como já apresentado, como na esfera intersetorial, não podem esbarrar em dificuldades sistêmicas. É essencial que os interessados em promover o meio ambiente saudável, para que obtenhamos a "cidade amigável ao meio ambiente", possuam a visão transdisciplinar. Akiko Santos leciona acerca da transdisciplinaridade:

\footnotetext{
A transdisciplinaridade é uma nova abordagem científica e cultural, uma nova forma de ver e entender a natureza, a vida e a humanidade. Ela busca a unidade do conhecimento para encontrar um sentido para a existência do Universo, da vida e da espécie humana. Se a Ciência Moderna significou uma mudança radical no modo de pensar dos homens medievais, a transdisciplinaridade, hoje, sugere a superação da mentalidade fragmentária, incentivando conexões e criando uma visão contextualizada do conhecimento, da vida e do mundo.

(...) A transdisciplinaridade transgride as fronteiras epistemológicas de cada ciência disciplinar e constrói um novo conhecimento "através" das ciências, um conhecimento integrado em função da humanidade, resgatando as relações de interdependência, pois a vida se constitui nas relações mantidas pelo indivíduo com o meio ambiente (SANTOS, 2005, p. 4).
}

Um bom exemplo de como a transdisciplinaridade auxilia na proteção do meio ambiente é relatado por Vanin (2012) em texto dedicado ao desenvolvimento sustentável nos municípios. Segundo ao autor para que o planejamento para a ocupação urbana seja ambientalmente sustentável é indispensável a congregação de diversos fatores científicos, mas não se afastando dos instrumentos jurídicos, posto que essenciais, refletindo que tal idealização, acerca da forma de ocupação urbana, deve ser pensada, também, sob o olhar do planejamento ambiental, urbanístico, arquitetônico, geológico, antropológico, espacial, climático, hidrológico, além da observação das prioridades das políticas públicas setoriais.

Em crítica à forma de como se planejam as cidades e sua ocupação, Alochio afirma que "o direito do urbanismo está prenhe de hipóteses segundo as quais a falta de interação 
acaba determinando o fracasso de alguns bons instrumentos jurídicos" uma vez que, se faz necessário "na construção do discurso do planejamento urbano, a elaboração de um trabalho de cooperação, coordenação e de tradução entre as diversas ciências envolvidas sem querelas de busca e supremacia", no entanto, os profissionais parecem "crer veementemente que sua ciência fornecerá as respostas necessárias ao cenário urbano" trazendo consigo uma "incrível pretensão de monopólio da verdade" (2010, p. 35-37). Ou seja, a incapacidade de aceitar a transdisciplinaridade como forma de alocação dos recursos humanos e financeiros acabam por decretar a falência dos planejamentos setoriais, claramente causado pela falta de interação entre os vários saberes e a empáfia do conhecimento superespecializado. Akiko Santos leciona acerca da complexidade dos fenômenos que:

\footnotetext{
Reconhecer a complexidade intrínseca aos fenômenos. A vida se manifesta na complexidade das relações que são estudadas separadamente pelas ciências, ciências exatas, biológicas e humanas. A interdependência é um princípio que sustenta a vida nesse planeta. Negar a interdependência entre Ciência e Cultura significa negar o sujeito, desvanecendo o sentido da vida. A transdisciplinaridade é a dissolução dos discursos homogeneizantes na ciência e na cultura.

(...) Tolerância e abertura são duas atitudes imprescindíveis no diálogo entre os diferentes saberes, as diferentes culturas, as diferentes teorias e os diferentes modos individuais de ser (SANTOS, 2005, p. 4).
}

A construção dos instrumentos jurídicos de planejamento da ocupação urbana não é uma empreitada somente para juristas e/ou para urbanistas, isoladamente, é uma tarefa que transpassa os mais diversos conhecimentos e disciplinas, já que ordenará a distribuição espacial de diversos aparelhos socioambientais (identificação de áreas de risco, de preservação permanente, zonas das águas, zonas habitacionais de interesse social) e, também, as questões que envolvam a prestação dos essenciais serviços de saúde, segurança e educação. Assim, as definições e alocações não devem ser estabelecidas por juristas e urbanistas, mas por uma gama de saberes que detém as informações e conhecimento sobre cada área, a partir de um diálogo e delimitação transdisciplinar. Alochio obtempera:

Esse processo de diálogo, interação, contestação e respeito às demais áreas do
conhecimento são indispensáveis para que o Plano Diretor, e os seus
desdobramentos, não se tornem "a busca de uma explicação do mundo como deveria
ser, e não de como ele é", evitando-se a construção de "normas abstratas,
independentes e transcendentes". A ideia de sugerir uma construção transdisciplinar
é tentar garantir que as normas jurídicas não incidam sobre o impossível, uma vez
que "as prescrições planejadoras devem ser possíveis, tanto material quanto
socialmente". Sendo assim, "a eleição desses critérios, no ato e no processo de
planejamento, só será possível transdisciplinarmente" (ALOCHIO, 2010, p. 41).

Ainda dentro do que propõe Alochio, quanto ao diálogo dos vários setores do conhecimento podemos citar uma importante iniciativa que está sendo configurada no âmbito 
municipal, mas sob a tutela de uma política nacional. Trata-se da gestão de áreas verdes urbanas, por meio do Cadastro Ambiental Urbano - CAU, que está sendo implantado em todo o país por intermédio do Programa Cidades + Verdes, do Ministério do Meio Ambiente, já alinhado à: a) Política Nacional de Meio Ambiente, que estabelece o zoneamento ambiental como um de seus instrumentos; b) ao Estatuto das Cidades, que institui o zoneamento ambiental como um dos instrumentos de planejamento territorial municipal; c) ao Código Florestal, que em sua Seção III do Capítulo IV trata do "Regime de Proteção das Áreas Verdes Urbanas".

A motivação da iniciativa partiu da constatação da ausência nas cidades de espaços considerados "verdes", e quando existentes, a sua degradação, tanto em seus aspectos urbanísticos quanto sociais, evidenciada pela perda das funções ecológicas de tais áreas, pela carência de manutenção e/ou conservação dos recursos naturais existentes. Não se pode olvidar da importância de tais áreas, não só no seu aspecto de paisagem e beleza, mas também na sua importância ecossistêmica, que são essenciais à saúde e à qualidade de vida nas cidades.

A diretrizes do Programa se cruzam com o interesse preservacionista e de materialização da proteção ambiental, tanto no ambiente natural, quanto no artificial, com intenso cruzamento de conhecimentos transdisciplinares, das quais podemos destacar: (i) o mapeamento e cadastramento das áreas verdes urbanas, para promoção e conservação da biodiversidade (geografia e engenharia geoespacial); (ii) promoção da cidadania ambiental, aumentando a acessibilidade e a participação da sociedade (sociologia política); (iii) promoção da sustentabilidade e da qualidade de vida da população por meio acesso equitativo, seguro e democrático e com infraestrutura que garanta acessibilidade e inclusão (políticas sociais); (iv) mitigação dos impactos dos eventos climáticos extremos e dos riscos socioambientais (climatologia); (v) potencialização dos serviços ecossistêmicos e estímulo à utilização de áreas verdes urbanas como soluções baseadas na natureza para recuperação de áreas degradadas e para prevenção, mitigação e superação de desafios sociais e ambientais locais (biologia); (vi) priorização do uso de espécies nativas na arborização urbana e na criação, recuperação, ampliação e manutenção de áreas verdes urbanas (botânica e etnobotânica); (vii) geração de trabalho, emprego e renda em atividades econômicas e culturais sustentáveis no âmbito do planejamento e gestão de áreas verdes urbanas (políticas sociais de pleno emprego); (viii) promoção da conservação da biodiversidade e do patrimônio 
genético e do uso sustentável das áreas verdes urbanas (genética); (ix) estímulo ao alinhamento entre políticas setoriais municipais e de articulação interfederativa para o planejamento e a gestão integrada de áreas verdes urbanas (direito constitucional); (x) priorização das áreas de vulnerabilidade social e ambiental no planejamento e gestão para criação, ampliação, recuperação, integração e manutenção de áreas verdes urbanas (ciências sociais e urbanismo); (xi) valorização do contexto local e da perspectiva sistêmica no planejamento e gestão das áreas verdes urbanas (gestão urbana, arquitetura e urbanismo); (xii) incentivo ao desenvolvimento e utilização de ferramentas tecnológicas nos processos de planejamento, monitoramento e gestão das áreas verdes urbanas (ciberciência).

A expansão urbana das cidades brasileiras não é acompanhada de processos de planejamento urbanístico e de gestão, o que gera uma conjuntura de degradação ambiental e, consequentemente, social, que afetam negativamente a qualidade de vida dos habitantes. A falta de planejamento, gestão e fiscalização ocasionam a ocupação de áreas de preservação permanente, além de áreas consideradas inapropriadas, como encostas e alagados, sujeitando os habitantes a perigos diversos.

Para se ter uma ideia da importância de realizar o planejamento urbano, segundo o Instituto Brasileiro de Geografia e Estatística - IBGE, o índice de urbanização brasileira atingiu $84,4 \%$ (oitenta e quatro vírgula quatro por cento) da população, ou seja, auxiliará na promoção da qualidade de vida de seus habitantes.

As normas brasileiras trazem o reconhecimento dos diversos serviços ecossistêmicos prestados por áreas verdes inseridas na malha urbana e de fato, essas áreas contribuem definitivamente para a melhoria da qualidade do ar, na mitigação dos impactos de eventos climáticos extremos, para eficiência da segurança hídrica, na redução de uma série de doenças cardíacas, pulmonares, psicológicas e relacionadas à poluição e degradação ambiental, aliás, existem estudos que indicam a relação entre áreas verdes e saúde humana, analisando evidências de melhorias na qualidade do ar, de aumento de atividades físicas, saúde respiratória e resiliência a doenças, de redução do estresse, e de uma maior coesão social, promovidos e estimulados por esses espaços.

O sítio do programa CAU, traz outros benefícios originados na existência de áreas verdes e florestas urbanas: a estabilização de superfícies por meio da fixação do solo pelas raízes das plantas; são obstáculos contra o vento canalizado; o equilíbrio de umidade e da temperatura; a proteção de nascentes, dos mananciais e da qualidade da água; é um abrigo 
para a fauna; a valorização visual e ornamental da paisagem urbana e do ambiente artificial; a segurança das calçadas como acompanhamento viário; como recreação; aumento do consumo de vegetais e frutas frescas, entre outros (BRASIL, 2021). Soma-se a isto, que ambientes arborizados e com abundância de espaços verdes se mostram mais agradáveis e geralmente, impactam positivamente na valorização imobiliária, atraindo residentes e investimentos, além de possibilitar sua sustentabilidade econômica. O programa já conta com mais de 3.700 (três mil e setecentas) áreas cadastradas, demonstrando que a iniciativa, por enquanto, está obtendo sucesso entre gestores municipais e cidadãos (PORTAL, 2021).

Pontua Passarelli que as áreas verdes de loteamentos, incluídas entre as áreas que passam ao domínio público, referidas no artigo 22, da Lei 6.766/1979, está intimamente ligado aos planos diretores e às leis municipais de uso do solo. José Afonso da Silva (SILVA, 2003. p. 190) destaca a importância destas áreas, aduzindo que elas não se destinam apenas:

\section{(...) à ornamentação urbana, mas como uma necessidade higiênica, de recreação e mesmo de defesa e recuperação do meio ambiente em face da degradação de agentes poluidores, e elemento de equilíbrio do meio ambiente urbano, de equilíbrio psicológico, de reconstituição da tranquilidade, de recomposição do temperamento, desgastados na faina estressante diária.}

A promoção do destacamento e da preservação das áreas verdes urbanas revela-se serviço da urbanização, conexa com a necessária proteção florestal, ao menos da parte que caberá à cidade, com o objetivo de "ordenar a coroa florestal em torno das grandes aglomerações, manter os espaços verdes existentes no centro das cidades, criar áreas verdes abertas ao público, preservar áreas verdes entre as habitações" em vista a contribuir para o equilíbrio do meio ambiente artificial, onde mais intensamente vive e trabalha o Homem (PASSARELI, 2010)

\section{Conclusão}

Neste estudo percorremos diversos temas que permeiam a forma de como se conquistar uma cidade amigável ao meio ambiente. A reflexão vale tanto quanto o estudo. Vivemos hoje na cidade, no Brasil somos quase duzentos milhões. Ponderando sobre o que foi lido, enxergamos que podemos mais, podemos fazer mais pelo ambiente natural na paisagem urbana. Já não se discute mais sobre a importância das áreas verdes no seio da urbe, a discussão agora cinge-se a quanto tempo suportaremos sobreviver em meio ao concreto, sem a luz verde. 
A cidade é feita de encontros, é pra isso que ela serve e foi essa a conclusão a que chegamos quando finalizamos os aspectos técnicos e jurídicos. Devemos promover os encontros.

Verificamos que cabe às esferas federal e estadual estabelecer normas gerais e referenciais técnicos para orientar a atuação dos municípios na gestão ambiental de seus territórios, mas cabe a todos, sem exceção, assegurar a consolidação de ações estruturantes voltadas à promoção de cidades sustentáveis e à superação de desafios urbanos no território nacional, por ser preceito ético e também constitucional, na perspectiva da obrigação de preservarmos e defendermos o meio ambiente, mantendo-o ecologicamente equilibrado, para as presentes e futuras gerações, a chamada equidade intergeracional.

O espaço público dos centros das cidades tornou-se o local de residência e de funcionamento da economia informal e dos excluídos que teimam em sobreviver numa sociedade que os ignora, mas também é o local onde conseguem sobreviver, pois é onde se tem maior acumulação de pessoas de passagem e também de desperdício (sobras em geral). É também o local de sobrevivência dos 'sem teto', da prostituição, do comércio de drogas ilícitas. A cidade permanece transformada num lugar de colossais contradições, depois de assistirmos à degradação generalizada dos espaços públicos decorrente da falta de planejamento, em que pese a existência de normas constitucionais acerca da sua obrigatoriedade.

A cidade que um dia foi concebida para preservar o coletivo dos males vindos de fora, agora serve para preservar os cidadãos do "inimigo interior". Os muros não estão mais para proteger as cidades e, sim, para blindar o indivíduo que agora se protege dentro de sua casa e de seus muros. Não convive, não compartilha e não partilha.

A cidade amigável é inclusiva, é aquela que permite a cada pessoa, livremente, ser diferentes personagens ou desempenhar diferentes papéis. A diversidade é condição para a tolerância e a tolerância o é para a inventiva e fecunda cidade criativa.

O meio ambiente saudável molda a cidade amigável. O meio ambiente preservado é a coroa de louros em torno da cidade e os seus centros verdes são seus diamantes.

\section{Referências}

ALOCHIO, Luiz Henrique Antunes. Plano Diretor e Estatuto da Cidade: Medidas Cautelares e Moratórias Urbanísticas. Belo Horizonte: Editora Fórum, 2010. 
BENJAMIN, Antonio Herman. Constitucionalização do ambiente e ecologização da

Constituição brasileira. In: CANOTILHO, José Joaquim Gomes; MORATO LEITE, José Rubens (orgs.). Direito constitucional ambiental brasileiro. São Paulo. Saraiva, 2007.

BENJAMIN, Antonio Herman. Princípio da proibição de retrocesso ambiental. Comissão de Meio Ambiente, Defesa do Consumidor e Fiscalização e Controle (org.). O princípio da proibição de retrocesso ambiental. disponível em http://www2.senado.gov.br/bdsf/item/id/242559. Acesso 19 dez. 2020. Brasília. Senado Federal. 2011.

BRASIL. Lei 6.938 de 31 de agosto de 1981, Política Nacional do Meio Ambiente. Brasília, DF: Presidência da República, 2020. Disponível em: http://www.planalto.gov.br/ccivil_03/leis/16938.htm. Acesso em: 16 jan. 2021.

BRASIL. [Constituição (1988)]. Constituição da República do Brasil de 1988. Brasília, DF: Presidência da República, [2020]. Disponível em: http://www.planalto.gov.br/ccivil_03/constituicao/constituicao.htm. Acesso em: 15 jan. 2021.

BRASIL. Supremo Tribunal Federal. ADI 3.540 MC. Brasília DF. Relator Celso de Mello, julgado em $1^{\circ}$ set. 2005, publicado em 03 fev. 2006.

BRASIL. Supremo Tribunal Federal. ADC 42. Novo Código Florestal. Brasília DF. Relator Luiz Fux, julgado em 28 fev. 2018. Plenário. Disponível em http://portal.stf.jus.br/processos/downloadPeca.asp?id=15340792543\&ext=.pdf. Acesso em 28 dez. 2020.

BRASIL. Supremo Tribunal Federal. Recurso Extraordinário 654833. Tema 999. Brasília DF. Relator Alexandre de Moraes, julgado em 20 abr. 2020. Plenário. Disponível em http://portal.stf.jus.br/processos/detalhe.asp?incidente=4130104. Acesso em 16 jan. 2021.

BRASIL. Lei 6.766 de 19 de dezembro de 1979. Dispõe sobre o Parcelamento do Solo Urbano e dá outras Providências. Brasília, DF: Presidência da República, 2021. Disponível em: http://www.planalto.gov.br/ccivil_03/LEIS/L6766.htm. Acesso em 05 de fev. 2021.

BRASIL. Supremo Tribunal Federal. ADI 478. São Paulo. Relator Carlos Velloso. DJ de 28 fev. 1997.

BRASIL. Lei 10.257 de 10 de julho de 2001. Regulamenta os arts. 182 e 183 da Constituição Federal, estabelece diretrizes gerais da política urbana e dá outras providências. Brasília, DF: Presidência da República, 2020. Disponível em:

http://www.planalto.gov.br/ccivil_03/LEIS/LEIS_2001/L10257.htm. Acesso em: 16 jan. 2021.

BRASIL. Lei 10.406 de 10 de janeiro de 2002. Institui o Código Civil. Brasília, DF: Presidência da República, 2020. Disponível em:

http://www.planalto.gov.br/ccivil_03/leis/2002/110406compilada.htm. Acesso em: 16 jan. 2021.

BRASIL. Lei 12.651 de 25 de maio de 2012. Dispõe sobre a proteção da vegetação nativa.

Brasília, DF: Presidência da República, 2020. Disponível em:

http://www.planalto.gov.br/ccivil_03/_ato2011-2014/2012/lei/112651.htm. Acesso em: 19 jan. 2021. 
BRASIL. Superior Tribunal de Justiça. Área de preservação permanente. Danos ambientais. Reflorestamento. Novo Código Florestal. Irretroatividade. AgRg no REsp 1.434.797/PR, $2^{\mathrm{a}}$ Turma, Rel. Min. Humberto Martins, j. 17.05.2016.

BRASIL. Superior Tribunal de Justiça. Administrativo e ambiental. Código Florestal. Aplicabilidade. A Lei n. 12.651/2012 (novo código florestal), que revogou a Lei n. 4.771/1965, não suprimiu a obrigação de averbação da área de reserva legal no registro de imóveis, mas apenas possibilitou que o registro seja realizado, alternativamente, no cadastro ambiental rural CAR. AgInt no AgInt no Agravo em Recurso Especial nº 1.241.128 - SP. Relator: Ministro Francisco Falcão. DJe, 02 abr. 2019. 2019.

BRASIL. Ministério do Meio Ambiente. Cadastro Ambiental Urbano. Disponível em http://portalcau.mma.gov.br/. Acesso em 31 jan. 2021.

CASTELNOU NETO, Antonio Manoel Nunes. Cidade e Natureza: uma introdução ao tema. Impulso. set-dez 2006, Vol. 17, p. 17-30. Disponível em http://search.ebscohost.com/login.aspx?direct=true\&db=foh\&AN=26878499\&lang=ptbr\&site=ehost-live. Acesso em 30 nov. 2020.

CIDH - CORTE INTERAMERICANA DE DIREITOS HUMANOS. Opinião Consultiva n. 23/2017 sobre "Meio Ambiente e Direitos Humanos". pp. 28- 29. Disponível em http://www.corteidh.or.cr/docs/opiniones/seriea_23_esp.pdf. Acesso em 25 jan. 2021.

FARIAS, Talden. A reserva legal ambiental no novo Código Florestal. 06 jul. 2019. Disponível em: https://www.conjur.com.br/2019-jul-06/reserva-legal-ambiental-codigo-florestal. Acesso em 29 dez. 2020.

FENSTERSEIFER, Tiago. O "diálogo das fontes" normativas na perspectiva do Direito Ambiental. 03 fev. 2021. Disponível em http://genjuridico.com.br/2021/02/03/dialogo-fontesnormativas-ambiental/?utm_source $=$ mktgen\&utm_medium=blog\&utm_campaign=bloggenjuridico-newsletter\#_ftnref15. Acesso em 05 fev. 2021.

IBGE. Instituto Brasileiro de Geografia e Estatística. Taxa de urbanização brasileira. Censo 2010. Disponível em ht-

tps://seriesestatisticas.ibge.gov.br/series.aspx?no=10\&op=0\&vcodigo=POP122\&t=taxaurbanizacao. Acesso em 31 jan. 2021.

LIMA, Frederico Henrique Viegas de. O delineamento da propriedade imobiliária na pósmodernidade. Série direito registral e notarial. Coordenadores: Sérgio Jacomino, Marcelo Augusto Santana de Melo e Francisco De Asís Palacios Criado. Vários autores. São Paulo. Saraiva, 2010.

MEIRELLES, Hely Lopes. Direito administrativo brasileiro. 42. ed. São Paulo. Malheiros, 2016.

MELO, Marcelo Augusto Santana de. O meio ambiente e o Registro de Imóveis. Série direito registral e notarial. Coordenadores: Sérgio Jacomino, Marcelo Augusto Santana de Melo e Francisco De Asís Palacios Criado. Vários autores. São Paulo. Saraiva, 2010. 
MILARÉ, Édis. Direito do ambiente [livro eletrônico]. 5. ed. -- São Paulo. Thomson Reuters Brasil, 2020.

MIRANDA. João Paulo Rocha. A Reserva Legal e o direito de propriedade. Registro de imóveis e meio ambiente. Série direito registral e notarial. Coordenadores: Sérgio Jacomino, Marcelo Augusto Santana de Melo e Francisco De Asís Palacios Criado. Vários autores. São Paulo. Saraiva, 2010.

NAKAMURA, André Luiz dos Santos. Regime jurídico das áreas institucionais. Revista dos Tribunais, 2017. RT vol. 979, maio 2017.

PASSARELLI. Luciano Lopes. O meio ambiente urbano e o Registro de Imóveis. Série direito registral e notarial. Coordenadores: Sérgio Jacomino, Marcelo Augusto Santana de Melo e Francisco De Asís Palacios Criado. Vários autores. São Paulo. Saraiva, 2010.

PORTAL DO RI. Cadastro Ambiental Urbano já registra mais de 3.700 áreas verdes. Disponível em https://www.portaldori.com.br/2021/02/02/cadastro-ambiental-urbano-ja-registramais-de-3-700-areas-verdes/. Acesso em 31 jan. 2021.

PORTUGAL, Lisboa. Como tornar Lisboa uma cidade amigável, segura e inclusiva para todos? Relatório da pergunta 2. Carta Estratégica 2010-2024. Câmara Municipal de Lisboa Portugal. Comissário Manuel Graça Dias. Disponível em cartaestrategica.cm-lisboa.pt. Acesso em 02 de fev. 2021.

PRIEUR, Michel. O princípio da proibição de retrocesso ambiental. Comissão de Meio Ambiente, Defesa do Consumidor e Fiscalização e Controle (org.). O princípio da proibição de retrocesso ambiental. Brasília. Senado Federal. 2011. Disponível em http://www2.senado.gov.br/bdsf/item/id/242559. Acesso 19 dez. 2020.

RAYMUNDI, Fabiano Camozzato. A publicidade garantida pelo registro de imóveis e a proteção ambiental. 2011. 155f. Dissertação (Mestrado Direito) Faculdade de Direito da Universidade de Caxias do Sul. Caxias do Sul.

SANTOS, Akiko. O que é transdisciplinaridade. Periódico Rural Semanal. Universidade Federal Rural do Rio de Janeiro, I parte: na semana de 22/28 de agosto de 2005; II parte: na semana de 29/04 de setembro de 2005.

SARLET. Ingo Wolfgang. FENSTERSEIFER, Tiago. O direito fundamental ao meio ambiente como cláusula pétrea do sistema constitucional brasileiro. Disponível em http://www.genjuridico.com.br. 25 ago. 2020. Acesso em 27 dez. 2020.

SCHEID, Cintia Maria. O princípio da função social da propriedade e sua repercussão na evolução da regularização fundiária urbana no ordenamento jurídico brasileiro. Revista de Direito Imobiliário. Vol. 83. Ano 40. p. 423-454. São Paulo. RT, jul.-dez. 2017.

SILVA, José Afonso da. Direito ambiental constitucional. 4. ed. São Paulo: Malheiros, 2003.

SOUZA, Eduardo Pacheco Ribeiro de. Constituição Cidadã: a função social da propriedade e o registro imobiliário. Revista de Direito Imobiliário. Vol. 85. Ano 41. p. 127-141. São Paulo: RT, jul.-dez. 2018. 
SZTAJN, Rachel. Função social da propriedade. Revista de Direito Imobiliário. Vol. 85. Ano 41. p. 405-414. São Paulo. RT, jul.-dez. 2018.

VANIN, Fabio Scopel. O Município Ambientalmente Sustentável: Instrumentos Jurídicos para a Garantia e as Barreiras Políticas para a Efetividade. Prisma Jur., São Paulo, v. 11, n. 2, p. 429453, jul./dez. 2012. 